\title{
Effects of Highlighting Text on the Reading Ability of Children with Developmental Dyslexia: A Pilot Study
}

\author{
https://doi.org/10.3991/ijet.v13i09.8736 \\ Hanae Ikeshita $\left({ }^{\bowtie}\right)$ \\ Sagami Women's University, Kanagawa, Japan \\ ikeshita_hanaedisc.sagami-wu.ac.jp \\ Sho Yamaguchi \\ Nagoya Gakuin University, Aichi, Japan \\ Toyoshi Morioka \\ 1-10drive, Inc., Kyoto, Japan \\ Takashi Yamazoe \\ Chiba University, Chiba, Japan
}

\begin{abstract}
Digital texts can be made accessible to children with developmental dyslexia by presenting them in a simplified layout, using suitable fonts, or using text highlighting that is synchronized with audio. However, the impact of this last method on readability (as measured by eye movement) for children with developmental dyslexia remains unknown; it is unclear whether the color and length of text highlighting influences readability. We examined these issues in two experiments with seven children with developmental dyslexia (aged 714 years). In the first experiment, we clarified the relation between readability and text highlighting with synchronous audio by measuring the eye movements of children with developmental dyslexia. Readability was determined using the frequency of eye fixations. In the second experiment, we determined which styles of text highlighting best supported digital text reading among children with developmental dyslexia. Digital texts were created using different text highlighting colors and band lengths, and then were read using Apple iBooks on a 9.7-inch Apple iPad Air. We observed that children with developmental dyslexia found it easier to read along when audio was synchronized with text highlighting, particularly for the highlighting style that used a blue band for whole sentences. The second experiment showed that children with developmental dyslexia found it particularly easy to read digital texts that were highlighted with blue or yellow bands, both for single sentences and for single words. The method of presenting visual information for reading might help children with developmental dyslexia read more easily.
\end{abstract}

Keywords-developmental dyslexia; visual information; accessibility; digital content; eye movement 


\section{Introduction and Background}

Developmental dyslexia is a learning disability with a specifically neurocognitive basis [1]. Dyslexic readers have difficulty with reading, writing, and spelling induced by their difficulty with associating phonemes with the symbols representing them in written graphemes. Developmental dyslexia is associated with numerous deficits in visual attention $[2,3,4,5]$. Low-level visual processing is also impaired in dyslexic readers [6]. About half of all children with developmental dyslexia complain of visual problems when attempting to read letters, such as letters appearing to blur, move around, and double [7]. Furthermore, when such children are able to see letters properly, reading can cause asthenopia and headaches [8]. Children with developmental dyslexia have been found to exhibit longer fixation durations and a greater number of fixations during reading than typically developing children [9]. All of these issues can lead to reading disability, which can prevent children from obtaining needed information from standard printed materials. In the treatment of reading difficulties with color filters, children with visual reading problems increased their reading accuracy with the use of blue filters while reading text printed on paper [7].

Modern technology has made it easy to change the background color when reading books using an electronic device. Drigas and Dourou found that multimedia combinations of different content forms, including text, audio, images, and video content, can support literacy learning as part of a multisensory approach by invoking the interest and motivation of users - especially users with developmental dyslexia [10]. Rello and Bigham examined the effect of using background colors on screen readability in dyslexic readers (from 18 to 60 years old); dyslexic readers have improved reading performance using cool background colors such as blue (R150, G173, B252), bluegrey (R219, G255, B241), and green (R219, G255, B241), rather than peach (R237, G221, B110), orange (R216, G211, B214), and yellow (R248, G253, B137) [11]. Rello and Baeza-Yates tested different text and backgrounds colors for reading on a screen (17-inch TFT monitor) with 46 readers with and 46 readers without dyslexia [12]. Participants with dyslexia had significantly longer fixation durations than the participants without dyslexia. However, text and background colors had no effect on fixation duration. Dyslexic readers preferred a text and background pairing of black text with a yellow background. Miniukovich, De Angeli, and Sulpizio, et al. conducted a review of Web readability guidelines. A user study with dyslexic and average readers reduced the 61-guideline set to a core of 12 guidelines; the guideline for text color was: "Use an off-white color for your background, like light gray or tan; use dark gray for text instead of pure black" [13]. That study also suggested that dyslexics' readability issues differed from the readability issues of average readers.

The development of e-books has made it possible for readers to personalize their style of reading and information gathering through the accessibility functions offered by computer operating systems. These accessibility functions include changing the text and background color combination, font size, and line spacing. E-books with such accessibility functions are considered more readable for individuals with developmental dyslexia [14, 15], and accessibility functions are key factors that facilitate reading for individuals with developmental dyslexia on mobile devices [16]. E-books can also 
easily integrate multimedia information not possible with paper media, such as sound (e.g., synchronizing sound with text highlighting), video (e.g., synchronizing video with subtitles), and 3D images. By utilizing such information, e-books can, for example, show individuals how to pronounce or understand certain words $[17,18]$.

Accessible e-books contain synchronized media files, such as those that provide audio narration. Examples of such materials are the Digital Accessible Information System (DAISY) format [19] and EPUB 3.0 [20] e-book formats based on Web protocols have text-highlighting functions; these functions can be applied to any band (e.g., from each letter to all letters in the book) and differ depending on the device manufacturer. Little has been reported on the effect of each multimedia information on readability. In particular, the impact on readability of highlighting texts in synchrony with audio narration has not been established. In addition, there are currently few digital texts using audio narration in synchrony with highlighting individual words in the digital content market such as Amazon or the iBooks Store. There are also few Japanese e-books for children available.

In the present study, we conducted two experiments to determine how text highlighting in e-books influences readability. In the first experiment, we clarified the relationship between readability and text highlighting with synchronous audio by measuring the eye movements of children with developmental dyslexia during digital text reading. Readability was determined via the frequency of eye fixations. In the second experiment, we applied paired comparisons, using Thurstone's scales [21], to determine which text highlighting styles best supported digital text reading for children with developmental dyslexia.

\section{Experiment 1}

\subsection{Methods}

Participants Seven Japanese children with developmental dyslexia aged 7-14 years (five boys and two girls) from Donguri Psycho Developmental Clinic for Developmental Disorders in Japan participated in Experiment 1. The clinic specializes in child neurology and developmental disorders. The study recruited participants from among the outpatients of the clinic. All children at the clinic had been diagnosed with developmental dyslexia and had normal or corrected-to-normal vision. The children were all native Japanese speakers and struggled with reading printed books. Written informed consent was obtained from parents as well as the children. This study was approved by Ritsumeikan University (Kinugasa-Jin-2014-27).

Apparatus The Eye Tribe (The Eye Tribe ApS) was used to record participants' eye movements. The eye-tracking rate was set at $30 \mathrm{~Hz}$, and the precision of tracking range was within 0.5 degrees (see Figure 1). The measurement data were recorded on a laptop computer. The digital text stimuli were shown on an Apple iPad Air (9.7-inch screen) with the e-book reader iBooks. Participants' eye movements were recorded as they read the digital text. 


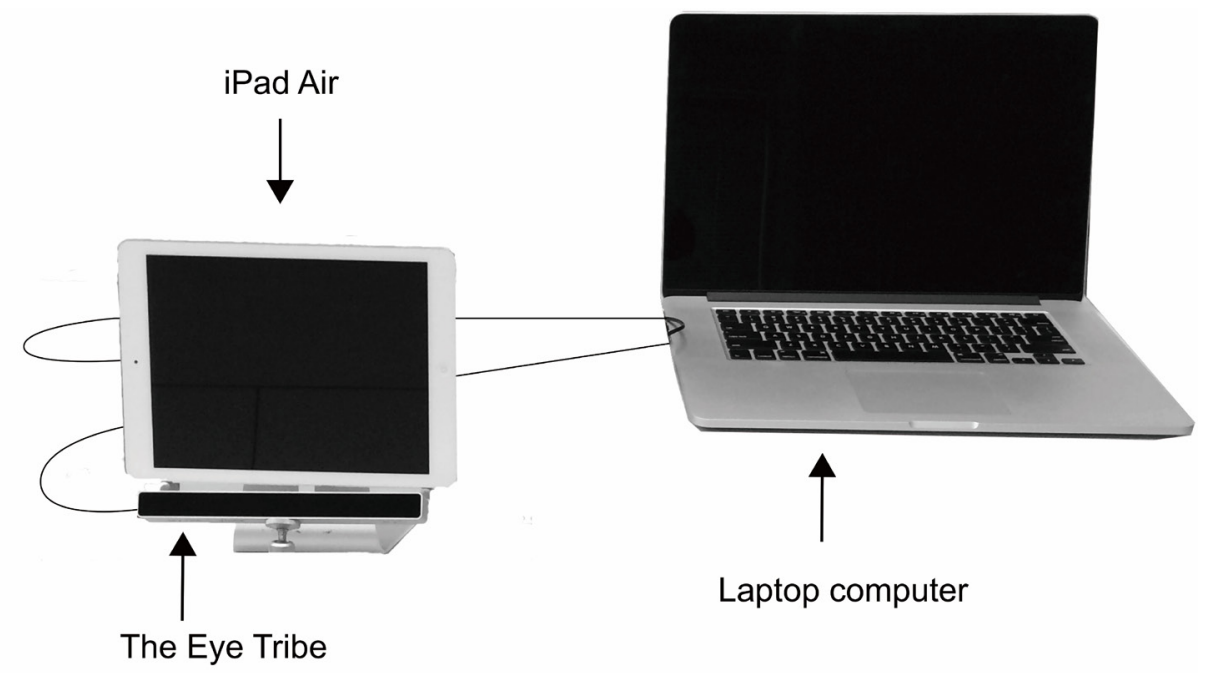

Fig. 1. Experimental setup

Stimuli The digital text stimuli contained sentences from Kabutomushi ("Beetle"; Nankichi Niimi, 1943). The Japanese book is copyright free, and its intended audience is all ages, from adult to children. The digital text included Japanese kanji, and the kanji characters included annotative ruby characters (small hiragana characters above the kanji to indicate pronunciation). Eight types of digital text stimuli were prepared from these sentences, including one type without audio narration or text highlighting; one type with audio narration but without text highlighting; and six types with audio narration and text highlighting (see Figure 2). These six types combined two highlighting styles and three visual indicators. The highlighting styles included highlighting one word or one sentence, while the visual indicators included underlining in black (RGB: 0, 0, 0), band highlighting in yellow (RGB: 255, 255, 0), and band highlighting in blue (RGB: 234, 234, 255). There was a 13:1 contrast ratio between the highlighting colors and text color. The audio narration was created using text-to-speech software (AITalk Plus, AI Inc.). The format of the digital text was EPUB 3.0, using the media overlay function [20]. Media overlay in EPUB 3.0 is able to highlight words or sentences and play audio narration synchronously with the highlighted text. None of the participants had read or heard the storybook before the current study. The storybook was selected from the public domain based on the quality of the book, the author's popularity in Japan, and the inclusion of a different book by the same author in Japanese school textbooks. 


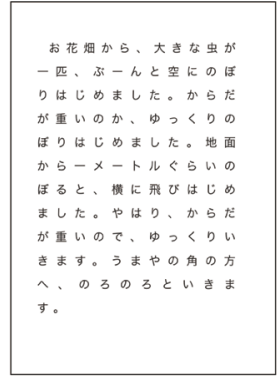

1

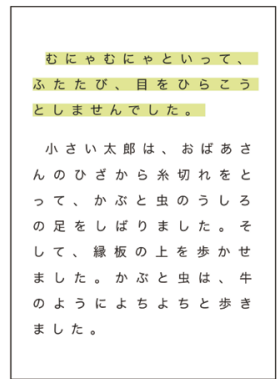

5

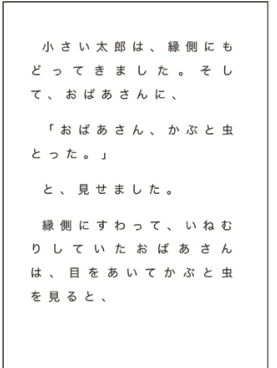

2

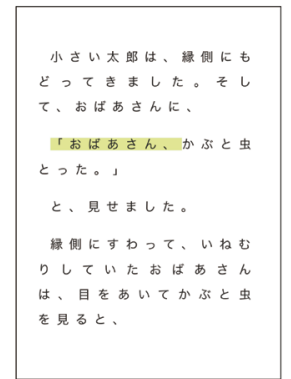

6

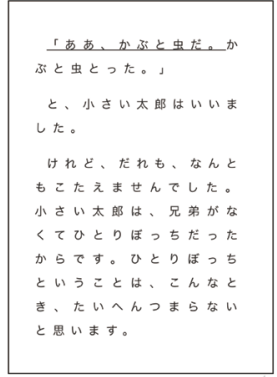

3

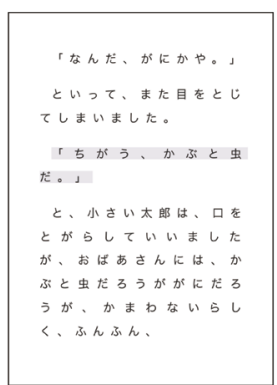

7

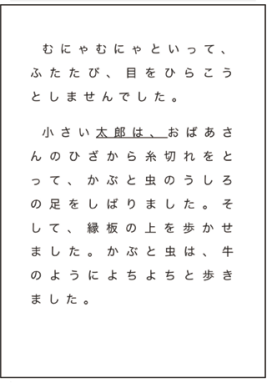

4

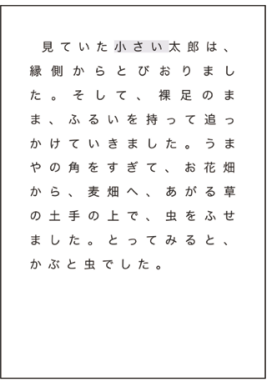

8

Fig. 2. Eight types of digital text stimuli: 1. (Without/NH), without audio narration and word highlighting; 2. (Narration), with audio narration and without word highlighting; 3. (U/S), with audio narration and single-sentence underlining; 4. (U/W), with audio narration and single-word underlining; 5. (Y/S), with audio narration and single-sentence highlighting with a yellow band; 6. (Y/W), with audio narration and single-word highlighting with a yellow band; 7. (B/S), with audio narration and single-sentence highlighting with a blue band; and 8 . (B/W), with audio narration and single-word high-

lighting with a blue band.

Procedure Participants were seated in front of the iPad Air, with a viewing distance of approximately $50 \mathrm{~cm}$. First, they were given instructions about the task and were asked to gaze at black circles on a white screen for around 20 seconds to calibrate the eye tracker. A nine-point calibration was performed. After the calibration was complete, participants were told that the task would begin, at which point they read the eight different types of digital text stimuli in sequence (see Figure 2 and Table 1). Upon completing the eight texts, participants rested for around 60 seconds. This period of reading and rest was considered a trial, and a total of eight trials were performed. The presentation order of the digital text types was randomized across participants, and the presentation order varied for each of the eight trials. 
Paper-Effects of Highlighting Text on the Reading Ability of Children with Developmental Dyslexia...

Table 1. Visual and Audio Indicators

\begin{tabular}{|l|c|c|c|}
\hline \multicolumn{1}{|c|}{ No. } & Audio narration & Visual indicator & Highlight style \\
\hline 1. Without/NH & - & - & - \\
\hline 2. Narration & Narration & - & - \\
\hline 3. U/S & Narration & Underline & One sentence \\
\hline 4. U/W & Narration & Underline & One word \\
\hline 5. $\mathrm{Y} / \mathrm{S}$ & Narration & Yellow & One sentence \\
\hline 6. Y/W & Narration & Yellow & One word \\
\hline 7. B/S & Narration & Blue & One sentence \\
\hline 8. B/W & Narration & Blue & One word \\
\hline
\end{tabular}

Data analysis People with developmental dyslexia tend to make more and longer fixations and more frequent regressive saccades during reading [22]. Numerous studies have indicated that their fixations are longer, and they make more regressions to re-examine words already read $[23 ; 24 ; 25 ; 26]$. Furthermore, their eye control during reading appears to be abnormal [27], and their fixations during reading are more frequent than those of average readers [28]. In the study of eye movement and cognitive processes, frequently used words receive shorter fixations than words that are infrequent [29]. Eye movement has been explored in spatial problem-solving tasks and has been supported in that domain as well as in reading [30]; eye movement has also been used to interpret gaze duration data in the development of the reading model. This last point is important because the number of fixations has been adopted as the chief measure of readability. Hence, in the present study, the main oculomotor parameter for readability was computed as the mean fixation count.

The frequency of fixations was analyzed using the eye movement data for both eyes for all participants. Fixations of shorter than $100 \mathrm{~ms}$ were removed from the analysis. The data of three participants were eliminated because of their poor quality; these data were noisy and did not provide clear readings and, as a result, could not be used. Four participants' data were used in the analysis. The data were analyzed using Friedman's two-way ANOVA; rank and pairwise comparisons were performed for each digital text type. The significance level was set at .05.

\subsection{Results}

The results of the mean fixation count during reading of digital texts are shown in Figure 3. We found higher fixation frequencies for the digital text stimuli without audio narration than for the seven types of stimuli with audio narration, $\chi^{2}(7)=$ $17.889, p=0.012$ (Friedman's test). Table 2 shows the results of the pairwise comparisons between the eight text conditions using Bonferroi tests. The results of these comparisons indicated that there was a significantly lower fixation count for the other digital text types (No. 2 to No. 8) than for the digital text stimuli without audio narration (No.1; $p<.01$, Table 2 ). We observed no significant differences between the other digital text types $(p>.05)$. 
Paper-Effects of Highlighting Text on the Reading Ability of Children with Developmental Dyslexia...

Table 2. Results of Pairwise Comparisons

\begin{tabular}{|c|c|c|c|c|}
\hline \multicolumn{2}{|c|}{ Digital text stimuli } & \multirow{2}{*}{ Mean difference (I-J) } & Standard error & $\boldsymbol{p}$ \\
\hline I. Without/NH & $\boldsymbol{J}$ & 82.250 & 12.957 & $0.001^{* *}$ \\
\hline & $3 . \mathrm{U} / \mathrm{S}$ & 84.000 & 12.957 & $0.001 * *$ \\
\hline & $4 . \mathrm{U} / \mathrm{W}$ & 89.750 & 12.957 & $0.001^{* *}$ \\
\hline & $5 . \mathrm{Y} / \mathrm{S}$ & 84.250 & 12.957 & $0.001^{* *}$ \\
\hline & $6 . \mathrm{Y} / \mathrm{W}$ & 87.750 & 12.957 & $0.001 * *$ \\
\hline & $7 . \mathrm{B} / \mathrm{S}$ & 82.000 & 12.957 & $0.001^{* *}$ \\
\hline & $8 . \mathrm{B} / \mathrm{W}$ & 54.000 & 12.957 & $0.009 * *$ \\
\hline
\end{tabular}

$p<0.01 * *$

Note. Eight types of digital text stimuli: 1 . Without/NH) without audio narration and word highlighting; 2 . Narration, with audio narration and without word highlighting; 3. U/S, with audio narration and underlining one sentence; 4 . U/W, with audio narration and underlining one word; 5 . Y/S, highlighting one sentence with a yellow band; $6, \mathrm{Y} / \mathrm{W}$ ) with audio narration and highlighting one word with a yellow band; 7 . $\mathrm{B} / \mathrm{S}$, with audio narration and highlighting one sentence with a blue band; and $8 . \mathrm{B} / \mathrm{W}$, with audio narration and highlighting one word with a blue band.

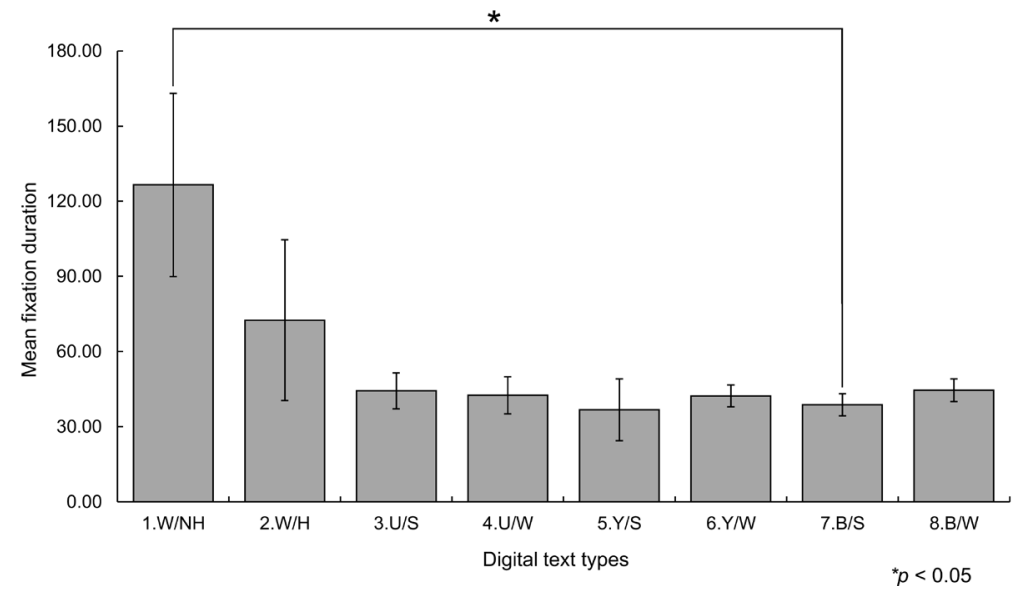

Fig. 3. Mean fixation count during reading of digital texts for children with developmental dyslexia

\section{Experiment 2}

\subsection{Methods}

Participants Seven Japanese children with developmental dyslexia (five boys and two girls), aged 7-14 years, participated. All children had participated in Experiment 
1. Written informed consent was obtained from parents and children. The study was approved by Ritsumeikan University (Kinugasa-Jin-2014-27).

Apparatus As in Experiment 1, the stimuli were displayed on an Apple iPad Air (9.7-inch screen) using iBooks, at a distance of $50 \mathrm{~cm}$ from the participants' faces.

Stimuli In this experiment, the digital text stimuli included sentences from Kabutomushi without audio narration. Seven types of the stimuli were used: one without text highlighting, and six types with text highlighting, which were the same as those used in Experiment 1(see Table 3).

Table 3. Experimental Stimuli from Experiment 2

\begin{tabular}{|l|c|c|}
\hline \multicolumn{1}{|c|}{ No. } & Visual indicator & Highlight style \\
\hline $1 . \mathrm{B} / \mathrm{S}$ & Blue & One sentence \\
\hline $2 . \mathrm{B} / \mathrm{W}$ & Blue & One word \\
\hline $3 . \mathrm{Y} / \mathrm{S}$ & Yellow & One sentence \\
\hline $4 . \mathrm{Y} / \mathrm{W}$ & Yellow & One word \\
\hline $5 . \mathrm{U} / \mathrm{S}$ & Underline & One sentence \\
\hline $6 . \mathrm{U} / \mathrm{W}$ & Underline & One word \\
\hline $7 . \mathrm{W} / \mathrm{H}$ & No highlight & No highlight band \\
\hline
\end{tabular}

Procedure Most of the experimental set-up was the same as that in Experiment 1, except for the presentation of digital text stimuli; the stimuli were shown side-by-side in random pairs on the screen. Participants were asked to judge "Is the readability of the text on the right greater than that on the left?" They performed this comparison 21 times in total.

Data analysis Participants' perceptions of readability were analyzed using Thurstone's Law of Comparative Judgment [21]. Thurstone's method provides onedimensional data based on preference judgments for two items, and it can be used to transform rank-ordered data. The simplest and most popular simplification is Thurstone's Case V model, which was used in this study because children were able to select stimuli easily. The Case $\mathrm{V}$ model assumes that all response options have equal variance and zero correlations. The results of the interval scores were plotted on an interval scale.

\subsection{Results}

The results of the rank-ordering are shown in Figure 4. The horizontal axis refers to the readability of digital text, with readability increasing from left to right. The highest scores were for the one-sentence highlighting with a blue band (see Table 3 , No. 1) and the one-word style with a blue band (No. 2). The other stimuli were as follows, in decreasing order of readability: the one-word style with a yellow band (No. 4), the one-sentence style with a yellow band (No. 3), the one-sentence style with underlining (No. 5), the one-word style with underlining (No. 6), and no highlighting (No. 7). 
We used a Kruskal-Wallis test, a nonparametric statistical method, to test for significance in the comparison between stimuli conditions, followed by each pair test for post hoc analysis. Statistical significance was accepted for a value of $p<.05$. The readability of digital text was significant in the color band condition $(r=17.38, p<$ .01 ). Post hoc analysis revealed the one-sentence highlighting with a blue band (No. 1), one-word style with a blue band (No. 2) and one-word with a yellow band (No. 4) scored higher than no highlighting (No.7; $p<.01$, Table 4). In addition, the onesentence highlighting with a blue band (No. 1), the one-word style with a blue band (No. 2), and the one-word with a yellow band (No. 4) were scored higher than the one-sentence style with underlining (No. $5 ; p<.05$, Table 4). The one-sentence style highlighting with a blue band (No. 1), one-word style with a blue band (No. 2) were higher score than the one-word style with underlining (No. 6; $p<.05$, Table 4).

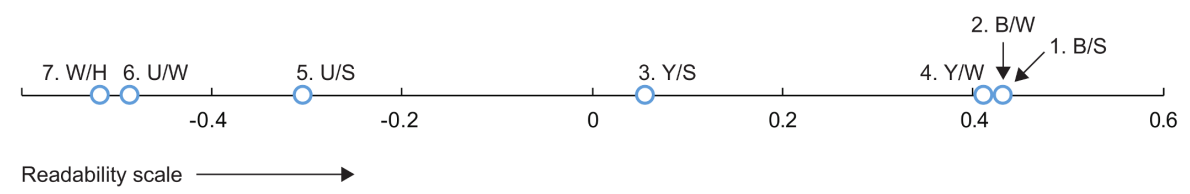

Fig. 4. Rank-ordering of digital text stimuli in terms of readability based on paired comparisons

Table 4. Results of Pairwise Comparisons

\begin{tabular}{|c|c|c|c|c|}
\hline \multicolumn{2}{|c|}{ Compared digital text stimuli } & \multirow{2}{*}{$\begin{array}{c}\text { Test statistics } \\
4.071\end{array}$} & \multirow{2}{*}{$\frac{\text { Standard error }}{7.527}$} & \multirow{2}{*}{$\begin{array}{c}\boldsymbol{p} \\
0.589 \\
\end{array}$} \\
\hline 7. W/H & 5. U/S & & & \\
\hline & 6. U/W & 6.714 & 7.527 & 0.372 \\
\hline & 3. $\mathrm{Y} / \mathrm{S}$ & 13.500 & 7.527 & 0.073 \\
\hline & 4. $\mathrm{Y} / \mathrm{W}$ & 20.143 & 7.527 & $0.007 * *$ \\
\hline & 1. $\mathrm{B} / \mathrm{S}$ & 21.786 & 7.527 & $0.004 * *$ \\
\hline & 2. $\mathrm{B} / \mathrm{W}$ & 21.786 & 7.527 & $0.004 * *$ \\
\hline \multirow[t]{5}{*}{ 5. U/S } & 6. U/W & -2.643 & 7.527 & 0.726 \\
\hline & 3. $\mathrm{Y} / \mathrm{S}$ & 9.429 & 7.527 & 0.210 \\
\hline & 4. Y/W & 16.071 & 7.527 & $0.033 *$ \\
\hline & 1. $\mathrm{B} / \mathrm{S}$ & 17.714 & 7.527 & $0.019 *$ \\
\hline & 2. $\mathrm{B} / \mathrm{W}$ & 17.714 & 7.527 & $0.019 *$ \\
\hline \multirow[t]{4}{*}{ 6. U/W } & 3. $\mathrm{Y} / \mathrm{S}$ & 6.786 & 7.527 & 0.367 \\
\hline & 4. $\mathrm{Y} / \mathrm{W}$ & 13.429 & 7.527 & 0.074 \\
\hline & 1. $\mathrm{B} / \mathrm{S}$ & 15.071 & 7.527 & $0.045^{*}$ \\
\hline & 2. $\mathrm{B} / \mathrm{W}$ & 15.071 & 7.527 & $0.045^{*}$ \\
\hline \multirow[t]{3}{*}{ 3. Y/S } & 4. $\mathrm{Y} / \mathrm{W}$ & -6.643 & 7.527 & 0.378 \\
\hline & 1. $\mathrm{B} / \mathrm{S}$ & 8.286 & 7.527 & 0.271 \\
\hline & 2. $\mathrm{B} / \mathrm{W}$ & 8.286 & 7.527 & 0.271 \\
\hline \multirow[t]{2}{*}{ 4. $\mathrm{Y} / \mathrm{W}$} & 1. $\mathrm{B} / \mathrm{S}$ & 1.643 & 7.527 & 0.827 \\
\hline & 2. $\mathrm{B} / \mathrm{W}$ & 1.643 & 7.527 & 0.827 \\
\hline 1. $\mathrm{B} / \mathrm{S}$ & 2. $\mathrm{B} / \mathrm{W}$ & 0.000 & 7.527 & 1.000 \\
\hline
\end{tabular}




\section{Discussion and Conclusion}

Combining highlighting with audio narration was found to be an effective method of facilitating readability of digital texts among children with developmental dyslexia in the present study. The objective evidence of Experiment 1 indicated that, when combined with audio narration, children with developmental dyslexia could easily read digital texts with highlighting, particularly the highlighting style with a blue band for the whole sentence sentences. These results accord with Stein's findings [7], wherein children with visual reading problems were able to improve their reading progress by viewing text without audio narration through yellow or blue filters; notably, some children actually benefited more from wearing the blue filters than the yellow filters.

In the previous studies, children with developmental dyslexia were able to read the text easily without audio narration, using color filters or background colors [7, 12]. We investigated the influence on children with developmental dyslexia of reading text with audio narration. In Experiment 1, we found that individuals with developmental dyslexia could not easily recognize the digital text stimuli without highlighting or audio narration, as compared with texts employing the highlighting and audio narration. Dyslexic children also tended to engage in longer fixations on letters when trying to decode words during reading sessions without audio narration [23]. This probably reflects the fact that dyslexic readers differ from normal readers in how they process visual information, such the way their eyes move across the page and even in the neurophysiology of their visual processing systems [31]. Prado, Dubois, and Valdois examined the eye movements of French dyslexic children (with reduced visual attention spans) and normal readers [28]; when the two groups were compared in visual search and text-reading performance, dyslexic children were found to exhibit longer fixations during reading. Their patterns of eye movement can also be differentiated from those of children who experience no reading problems [32], suggesting that eye movement patterns might be used to facilitate earlier diagnosis of developmental dyslexia $[32,33]$. Scheneps et al. also reported that shorter lines reduced the number of regressions and generally improved dyslexics' reading speed and comprehension, simply by reducing the probability of perceiving text crowding in previously fixatedon locations [16]. Thus, children with developmental dyslexia could be confused by having to rely solely on the visual information of texts.

The subjective evidence of Experiment 2 similarly indicated that children with developmental dyslexia found it particularly easy to read digital texts highlighted with blue or yellow bands, both for single sentences and for single words. Notably, digital texts that used underlining had approximately the same readability levels as did texts without highlighting. However, our studies investigated small samples; these results suggest that readability can be improved through a variety of methods. Readability may also differ for each child with developmental dyslexia. There are, however, currently few digital texts using audio narration synchronized with single-word highlighting in the digital content market. To aid readers, e-book reading devices might include or expand functions that allow for customization of the reading text. In addi- 
tion, e-book designers might concentrate on using plain text rather than imaged text, because imaged texts do not support media overlay functions.

The data ware based on a small sample size and a wide age range in the present study. This experiment did not investigate the effect of combining highlighting with audio narration in children with typical development, although this is planned for future investigation; we plan to test across a wider sample composed of people of comparable age and reading levels. This additional study will further clarify the relationship between reading comprehension and digital text reading in children with developmental dyslexia.

\section{$5 \quad$ Acknowledgment}

The authors are grateful to the participants of our research project. This research was partially supported by The Telecommunications Advancement Foundation (2013).

\section{References}

[1] Lyon, G. R., Shaywitz, S. E., \& Shaywitz, B. A. (2003). A definition of dyslexia. Annals of Dyslexia, 53(1), 1-14. https://doi.org/10.1007/s11881-003-0001-9

[2] Facoetti, A., Zorzi, M., Cestnick, L., Lorusso, M., Molteni, M., Paganoni, P., . . . Mascetti, G. G. (2006). The relationship between visuo-spatial attention and nonword reading in developmental dyslexia. Cognitive Neuropsychology, 23(6), 841-855. https://doi.org/10.1080/02643290500483090

[3] Facoetti, A., Corradi, N., Ruffino, M., Gori, S., \& Zorzi, M. (2010). Visual spatial attention and speech segmentation are both impaired in preschoolers at familial risk for developmental dyslexia. Dyslexia, 16(3), 226-239. https://doi.org/10.1002/dys.413

[4] Facoetti, A., Ruffino, M., Peru, A., Paganoni, P., \& Chelazzi, L. (2008). Sluggish engagement and disengagement of non-spatial attention in dyslexic children. Cortex, 44(9), 1221 1233. https://doi.org/10.1016/j.cortex.2007.10.007

[5] Franceschini, S., Gori, S., Ruffino, M., Pedrolli, K., \& Facoetti, A. (2011). A causal link between visual spatial attention and reading acquisition. Current Biology 22(9), 1-6. doi:10.1016/j.cub.2012.03.013. https://doi.org/10.1016/j.cub.2012.03.013

[6] Boden, C., \& Giaschi, D. (2007). M-Stream deficits and reading-related visual processes in developmental dyslexia. Psychological Bulletin, 133(2), 346--366. https://doi.org/10.1037/ 0033-2909.133.2.346

[7] Stein, J. (2014). Dyslexia: the role of vision and visual attention. Current Development Disorder Reports, 1(4), 267-280. https://doi.org/10.1007/s40474-014-0030-6

[8] Wilkins, A. J. (1995). Visual stress. Oxford: Oxford University Press. https://doi.org/10.1093/acprof:oso/9780198521747.001.0001

[9] Hutzler, F., \& Wimmer, H. (2004). Eye movements of dyslexic children when reading in a regular orthography. Brain and Language, 89(1), 235-242. https://doi.org/10.1016/S0093934X(03)00401-2

[10] Drigas, A., \& Dourou, A. (2013). A review on ICTs, e-learning and artificial intelligence for dyslexic's assistance. International Journal of Emerging Technologies in Learning (iJET), 8(4), 63-67. https://doi.org/10.3991/ijet.v8i4.2980 
Paper-Effects of Highlighting Text on the Reading Ability of Children with Developmental Dyslexia...

[11] Rello, L., Bigham, J.P. (2017). Good Background Colors for Readers: A Study of People with and without Dyslexia. Proceedings of the 19th International ACM SIGACCESS Conference on Computers and Accessibility, Baltimore, Maryland, USA - October 20November 01, 2017. ACM New York, NY., 72-80. https://doi.org/10.1145/3132525 .3132546

[12] Rello, L. \& Baeza-Yates, R. (2017). Universal Access in the Information Society. 16(1), 29-79. https://doi.org/10.1007/s10209-015-0438-8 https://doi.org/10.1007/s10209-0150438-8

[13] Miniukovich, A., De Angeli, A., Sulpizio, S., \& Venuti, P. (2017). Design Guidelines for Web Readability. Proceedings of the 2017 Conference on Designing Interactive Systems, Edinburgh, United Kingdom - June 10 - 14, 2017. ACM New York, NY, 285-296 https://doi.org/10.1145/3064663.3064711

[14] Evett, L., \& Brown, D. (2005). Text formats and Web design for visually impaired and dyslexic readers - clear text for all. Interacting with Computers, 17(4), 453-472. https://doi.org/10.1016/j.intcom.2005.04.001

[15] McCarthy, J. E., \& Swierenga, S. J. (2010). What we know about dyslexia and Web accessibility: A research review. Universal Access in the Information Society, 9(2), 147-152. https://doi.org/10.1007/s10209-009-0160-5

[16] Schneps, M. H., O’Keeffe, J. K., Heffner-Wong, A., \& Sonnert, G. (2010). Using technology to support STEM reading. Journal of Special Education Technology, 25(3), 21-33. https://doi.org/10.1177/016264341002500304

[17] De Jong, M. T., \& Bus, A. G. (2003). How well suited are electronic books to supporting literacy? Journal of Early Childhood Literacy, 3(2), 147-164. https://doi.org/10.1177/14 687984030032002

[18] Lewin, C. (2000). Exploring the effects of talking book software in UK primary classrooms. Journal of Research in Reading, 23(2), 149-157. https://doi.org/10.1111/1467$\underline{9817.00111}$

[19] National Information Standards Organization. (2005). Specifications for the digital talking book. Baltimore, MD: Author. Retrieved from http://www.niso.org/apps/group public/ download.php/14650/Z39 86 2005r2012.pdf.

[20] International Digital Publishing Forum. (2011). EPUB Media Overlays 3.0. Seattle, WA: Author. Retrieved from http://www.idpf.org/epub/30/spec/epub30-mediaoverlays.html.

[21] Thurstone, L. L. (1927). Psychophysical analysis. American Journal of Psychology, 38, 368-389. https://doi.org/10.2307/1415006

[22] Hyona, J., \& Olson, R. K. (1995). Eye fixation patterns among dyslexic and normal readers: effects of word length and word frequency. Journal of Experimental Psychology: Learning, Memory, and Cognition, 21(6), 1430-1440. https://doi.org/10.1037/02787393.21.6.1430

[23] Rayner, K. (1985). Do faulty eye movements cause dyslexia? Developmental Neuropsychology, 1(1), 3-15. https://doi.org/10.1080/87565648509540294

[24] Eden, G F., Stein, J. F., Wood, H. M., \& Wood, F. B. (1994). Differences in eye movements and reading problems in dyslexic and normal children. Vision Research, 34, 13451358. https://doi.org/10.1016/0042-6989(94)90209-7

[25] Solan H. A., Ficarra, A., Brannan, J. R., \& Rucker, F. (1998). Eye movement efficiency in normal and reading disabled elementary school children: effects of varying luminance and wavelength. Journal of American Optometric Association, 69, 455-464.

[26] Kirkby, J. A., Webster, L. A. D., Blythe, H. I., \& Liversedge, S. P. (2008). Binocular coordination during reading and non-reading tasks. Psychological Bulletin. 134(5), 742-763. https://doi.org/10.1037/a0012979

[27] Vidyasagar T. R. (2004). Neural underpinnings of dyslexia as a disorder of visuo-spatial attention. Clinical \& Experimental Optometry. 87, 4-10. https://doi.org/10.1111/j.14440938.2004.tb03138.x 
Paper-Effects of Highlighting Text on the Reading Ability of Children with Developmental Dyslexia...

[28] Prado, C., Dubois, M., \& Valdois, S. (2007). The eye movements of dyslexic children during reading and visual search: Impact of the visual attention span. Vision Research, 47(19), 2521-2530. https://doi.org/10.1016/j.visres.2007.06.001

[29] Inhoff, A.W. \& Rayner, K. (1986). Parafoveal word processing during eye fixations in reading: Effects of word frequency. Perception \& Psychophysics, 40(6), 431-439. https://doi.org/10.3758/BF03208203

[30] Carpenter, P.A. (1976). Eye fixations and cognitive processes. Cognitive Psychology, 8(4), 441-480. https://doi.org/10.1016/0010-0285(76)90015-3

[31] Conlon, E. G., Sanders, M. A., \& Wright, C. M. (2009). Relationships between global motion and global form processing, practice, cognitive and visual processing in adults with dyslexia or visual discomfort. Neuropsychologia, 47(3), 907-915. https://doi.org/10.1016/ j.neuropsychologia.2008.12.037

[32] Pavlidis, G. T. (1985). Eye movements in dyslexia: their diagnostic significance. Journal of Learning Disabilities, 18(1), 42-50. https://doi.org/10.1177/002221948501800109

[33] Vagge, A. Cavanna, M., Traverso, C. A., \& Iester, M. (2015). Evaluation of ocular movements in patients with dyslexia. Annals of Dyslexia, 65(1), 24-32. https://doi.org/10.1007/ s11881-015-0098-7

\section{Authors}

Hanae Ikeshita is an associate professor at the Department of Information and Media Studies, Faculty of Arts and Sciences, Sagami Women's University. She received her Ph.D. in Global Information and Telecommunication Studies from Waseda University in 2011. She has developed various literacy-learning methods for individuals with developmental dyslexia, such as accessible digital picture books.

Sho Yamaguchi is an associate professor at the Faculty of Commerce in Nagoya Gakuin University, Japan. He has taught courses such as "Business and Information." His research interests include the economics of information and communications media, the accessibility of information, and communication.

Toyoshi Morioka is Chief Technical Officer of 1-10drive Corporation. He has worked on development and research of visual technology devices. He received a B.E. and M.E. in image Engineering from Tokyo Polytechnic University, Japan, in 2004 and 2006, respectively. He completed a doctoral program ABD at Tokyo Polytechnic University in 2009 . He began researching image processing, image recognition, and signal processing at Newly Corporation in 2009, and joined the 1-10design Incorporation group in 2014. He was established 1-10drive Corporation in 2015.

Takashi Yamazoe has been a project researcher at Institute for Global Prominent Research, Chiba University, since 2017. His recent research interests include the visual perception and ergonomics of head-mounted displays. He received his B.E. in Image Engineering from Tokyo Polytechnic University in 2004. He received his M.S. and Ph.D. in Global Information and Telecommunication Studies from Waseda University in 2007 and 2013, respectively.

Article submitted 23 April 2018. Resubmitted 08 June 2018. Final acceptance 10 June 2018. Final version published as submitted by the authors. 